\title{
Ex-situ Conservation of the some Medicinal Plants of Georgia
}

\author{
Tsira Mikatadze-Pantsulaia ${ }^{1}$, Tolkha Shetekauri ${ }^{1}$ and Mariam Kikvidze ${ }^{1,2}$ \\ 1. Department of Plant Conservation, National Botanical Garden of Georgia, Tbilisi, Georgia \\ 2. Institute of Ecology, School of Natural Sciences and Engineering, Ilia State University, Tbilisi, Georgia
}

\begin{abstract}
The present work concerns with ex-situ Conservation issues study of the three economical species Cyclamen vernum Sweet is a synonym of Cyclamen coum subsp.caucasicum (K. Koch) O. Schwarz (Primulaceae) Helleborus caucasicus A. Braun (Ranuculaceae) and Paeonia caucasica Schipcz) Schipcz. Is synonym of Paeonia dauricasubsp. Coriifolia (Rupr.) D. Y. Hong distribution in Georgia. These species are under strong anthropogenic stress, Its populations are collected in nature as a decorative and traditional medicinal properties.It is of urgent necessity to take conservation measures for these species through both ex-situ and in-situ protection methods. For this purpose it is of critical importance to collect data on the distribution of the above species and vitality and fertility of their populations. Processes of seed production and seed multiplication have been studied. The ex-situ base of the seed and live collection bank was created. The work is done in Great Britain within the framework of the "Millennium" Seed Bank Partnership of Kew Botanical Garden. The seeds are placed in the National Seed Bank, duplicates together with Herbarium sample are sent in the millennium seed bank. The live collection obtained from seeds is placed on the collection plot of Plant Conservation Department of the National Botanical Garden of Georgia
\end{abstract}

Key words: Ex-situ conservation, medicinal plants, seed bank,life collection.

\section{Introduction}

Georgia's flora comprises more than 4100 species (4133) of the vascular plants. High endemism level of Georgia s flora reflects its richness $-21 \%$ of the local flora is endemic and consists of about 900 species. Among them about 600 species are endemic to the Caucasus and about 300 are endemic to Georgia [1]. The Caucasus, and Georgia, in particular, has been attributed to biodiversity "hotspots", areas which cover only $1.4 \%$ of the Earth's land area but are home to $44 \%$ of known plant species [1,2].

Flora of Georgia is known to contain a remarkably high number of species of medicinal value, with over 700 species utilized in Georgian traditional medicine and 200 taxa registered in the official pharmacopoeia $[1,3]$.

Hundreds of Georgian economical plant species are

Corresponding author: Tsira Mikatadze-Pantsulaia, Ph.D., Head of the Department of Plant Conservation, research fields: wild plants conservation. E-mail: tsirapantsu@yahoo.com. threatened with extinction or exposed to risk of genetic erosion. The vast majorities of medicinal plants in Georgia are harvested in the wild and in some cases are even overexploited. Due to economical difficulties in Georgia, wild flora and habitats are under the permanent anthropogenic pressure such as tree felling, overharvesting of wild species, etc. that causes deterioration and fragmentation of habitats and extinction of many species of medicinal value. It is of urgent necessity to take conservation measures for these species through both ex-situ and in-situ protection methods. For this purpose it is of critical importance to collect data on the distribution of the above species and vitality and fertility of their populations.

In 2001, was establishment the Caucasus Regional Seed Bank (CRSB) the establishment of seed bank was the part of collaborative project between Georgian botanists and colleagues from Missouri Botanical Garden "Sustainable Use \& Conservation of 
Medicinal Plant Resources in the Republic of Georgia". As an output of the above projects, seeds of 150 endemic and rare medicinal plants were collected and deposited to the CRSB.

The next step in the further developing of the Caucasus Regional Seed Bank was collaboration with Kew's Millennium Seed Bank Partnership (MSBP) which commenced in 2005 and continues to date.

Nowadays the Bank of Caucasus is called the National Seed Bank (NSB) and there is a Plant Conservation Department.

Study of biological peculiarities of medicinal plants, Investigation of capacity for reproduction by seed, creation of living collections, propagation and ex-situ conservation are priorities of our work, as hundreds of plant species in Georgia are threatened with extinction or serious genetic erosion. The vast majority of medicinal plants in Georgia are collected from wild habitats, and in some cases, are heavily exploited, potentially threatening further existence of selected species. Increasing pressure on natural areas, due to increased deforestation, erosion, air pollution and dam-building, threatens the habitats of important medicinal plants.

The present work dealt with of some decorative and traditional medicinal properties species Helleborus caucasicus A. Braun (Accepted species in Plant list); DD - Status in Red list [4] Cyclamenvernum Sweet is a synonym of Cyclamencoum subsp. Caucasicum (K. Koch) O. Schwarz (in Plant list); NE - Status in Red list (4) The Cy. vernum very different from Cy. coum populations that researcher [5] Cy. vernum calls the Georgians Cyclamen.Paeonia caucasica (Schipcz) Schipcz. Is synonym of Paeonia dauricasubsp. Coriifolia (Rupr.) D. Y. Hong in Plant list; LC status in Red list [4]

They are included in the Red List (4) with different status, today's the target species populations are not sufficiently assessed. In nature their populations are invaluable, they require protection.

The species that which we studied is not characterized local distribution. They are widespread almost all regions of Georgia (see map) and everywhere is under stress. People collect and sell their bouquets, plant roots; tubers are collected and donated in the phytotherapy pharmacies.

$E x$-situ conservation activities for these species were carried out for the first time as well. Processes of seed formation of a species and growth of seedlings developed from seeds are known to be influenced by different factors, such as, climate, human impact, genotype factors and characteristic to particular species. This is a complex of factors, which affect the species directly or indirectly and are responsible for its success or failure in its distributional range. This research was aimed at the assessment of self-renewal capacity of three species of the different genus the establishment of their seed bank and ex-situ living collections.

\section{Materials and Methods}

Flowering biology and seed forming capacity were studied on plant material of Helleborus Cyclamen, Paeonia, and their natural distribution places.

Helleborus caucasicus is endemic to Caucasus; perennial rhizome grass; flowering in January February fruit - bearing in May; in rhizome and roots contains glycosides, which has a similar effect on heart as strophanthin; grows in middle mountain zones, near forests $[3,6-8]$.

Cyclamen vernum - perennial tuber grass; flowering in February-March, produces fruit in May-June; grows in forests (hornbeam, beech forests), open slopes of low and upper mountain zones; tubers contains saponine cyclamen and glycosides; used in Georgian folk medicine against gynecological and liver diseases, arthritis, neuralgia, etc. [3, 6-8].

Paeonia caucasica - is endemic to Caucasus (in Georgian Checklist); perennial rhizome grass; flowering in May-June, produces fruits in July; in Georgian used for folk medicinal purposes; its rhizomes contain essential oils, methyl salicynide, 
benzoin, salicylic acids, etc. rhizome tincture is used a sedative means against neurasthenia, insomnia, pores and hypochondria; treatment of gastric disorders and epilepsy [3, 6-8].

All three species are very decorative and its flowers for sale as bouquet. The work has begun about 10 years ago and continues

Investigations were carried out both in the field and under laboratory conditions using the approved novel methods of embryology and reproduction biology. Observations on seed germination and seedling biology were made on seedlings sown on Petri dishes and in pots outdoors. Questions concerning flowering and pollination were studied using a technique by. Material for embryological investigations was processed and studied using common cyto-embryological methodology. Pollen germination on artificial medium was tested on $10-15 \%$ saccharose solution at $20-25^{\circ} \mathrm{C}$, maximum exposition time 24 hours. Temporal fixation required for embryological studies was done from the beginning of flower shoot development to final flowering. The following fixing agents were used: FAA and FPA. [9] Microscopic studies were carried out using CARL ZEISS (Germany) light microscope and OMAX 40X-2500X/M837ZL.

Seed productivity was determined according to a technique by 50 fruits with seeds already entered into the maturation phase were collected from each population and developed seeds as well as undeveloped ovules were counted. Observations on seed germination capacity were made at ambient temperature $\left(18-20^{\circ} \mathrm{C}\right)$. Germination capacity, seed collection and deposition in Seed Bank (long-term storage at minus 20 degrees) was performed after [11-13].

Live collections are created of the ex-situ site, collection plot of the Department of Plant of NBGG was as following: GPS coordinates at $41^{\circ} 41^{\prime} 150^{\prime \prime} \mathrm{N}$, $44^{\circ} 48^{\prime} 140^{\prime \prime} \mathrm{E}$, above sea level $504 \mathrm{~m}$; mean annual temperature $12.6^{\circ} \mathrm{C}$, mean minimum temperature in January $-0.5^{\circ} \mathrm{C}$ and absolute minimum $-18^{\circ} \mathrm{C}$; mean annual precipitation $518 \mathrm{~mm}$; summer and winter moderately dry.

\section{Results and Discussion}

In the nature of the species is directly related to the possibility of their self-renewal (from seeds or vegetative) with environmental stress factors. This combination of factors determines the species' conservation status.

The main thing is to keep genplasm multiplication of the species by seed. We know last year's ours research (Cy. Vernum) the possibilities (formation of female and male generative structures, as well as with normal course of pollination and fertilization) of the seed reproduction of target species [14].

We have studied potential and real seed production opportunities in target species; Seeds germination and propagation percent in laboratory conditions; Seeding seeds in pots and in the open ground to create of the ex-situ living collections.

Helleborus caucasicus Despite the fact that the pollination/fertilization coincides with the very cold period (of the seed reproduction is good. Its male and female generative organs develop normally, pollen is characterized by high fertility (Figs. 7, 8). H. caucasicus has been chosen for self-pollination as an easy way to seed reproduction.

Seeds of $\mathrm{H}$. caucasicus are characterized by good germination and sprouting capacity: $98 \%$ in Petri dishes and $92-95 \%$ in pots and ground

Cyclamen vernum - As a result of studying processes of seed production revealed: The number of the ovules are 24, 36 and maximum 48 (potential possibility); The number of real seeds is minimum -18 , maximum $24.75-84 \%$ of ovules produce seeds which indicate that pollination/fertilization processes proceed well.

Actual seed production of the species is close to is potential capacity. We studied the germination and sprouting ability of the seeds in a laboratory in Petri 


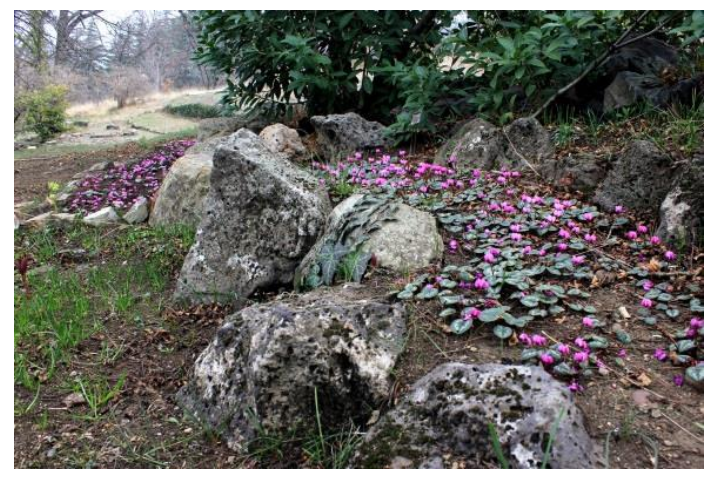

Fig. 1 Cy. vernum - in collection.

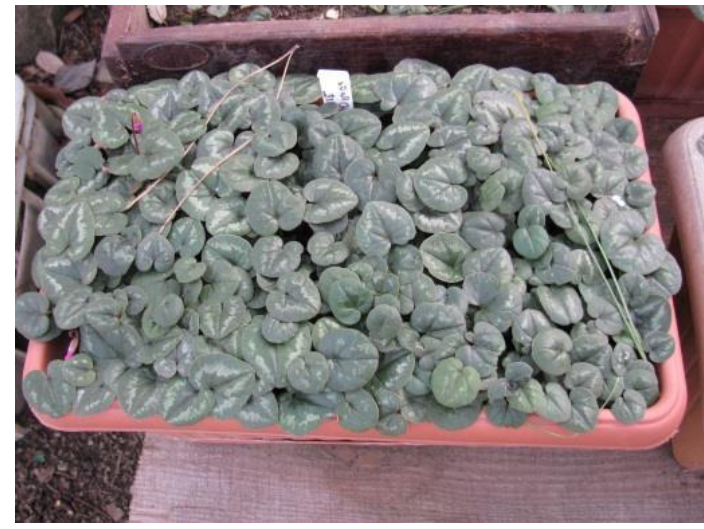

Fig. 2 Cy. vernum from seeds.

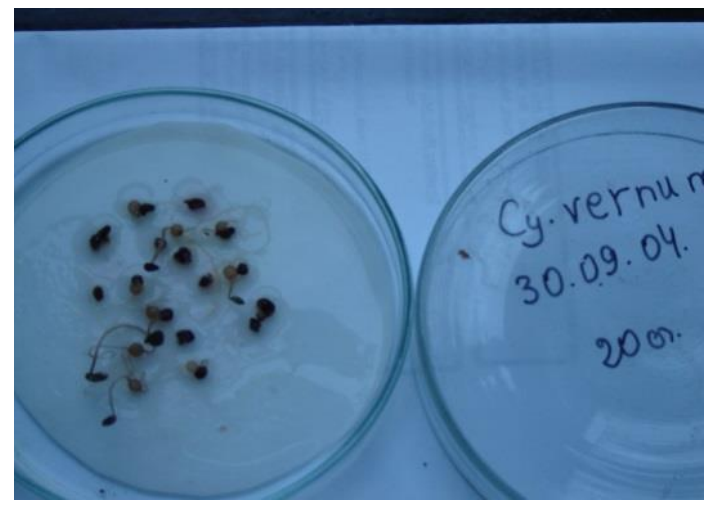

Fig. 3 Seeds germination Cy. Vernum.

dishes, pots and ground. Seeds of C. vernum are Characterized by good germination and sprouting capacity: 95-98\% in Petri dishes (Fig. 3) and 85-88\% in pots and ground (Fig. 2). The cyclamen populations are multiplied only by the seed, of the vegetative (Cut the tuber) can only be in laboratory conditions (Fig. 5). Plant developed from seed starts flowering on the $3^{\text {th }}$ year.

Paeonia caucasica - Potential seed production is more than a real fertile seed. Potential seed giving

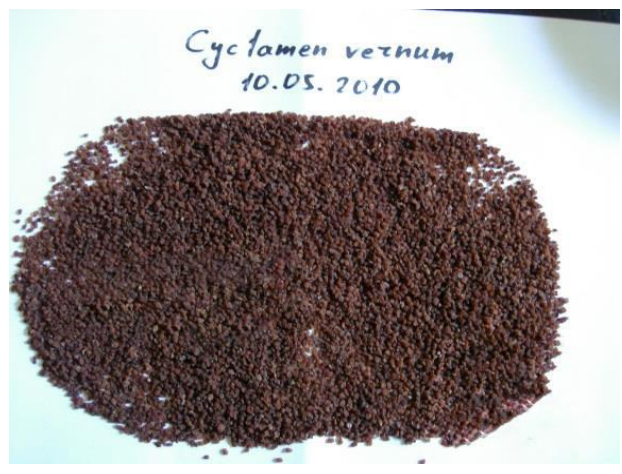

Fig. 4 Ripe seeds of Cy. Vernum.

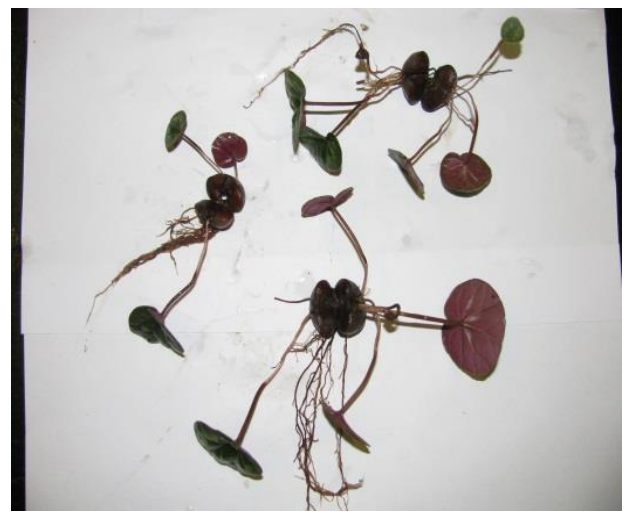

Fig. 5 Seedlings from tubers cat of Cy. Vernum.

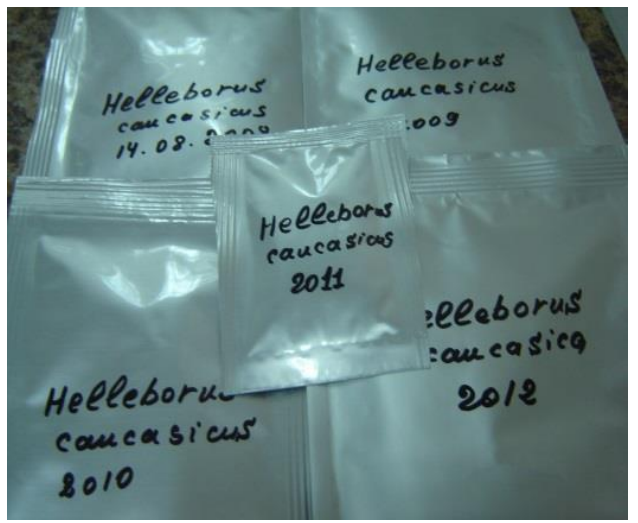

Fig. 6 H. caucasicus in seed bank.

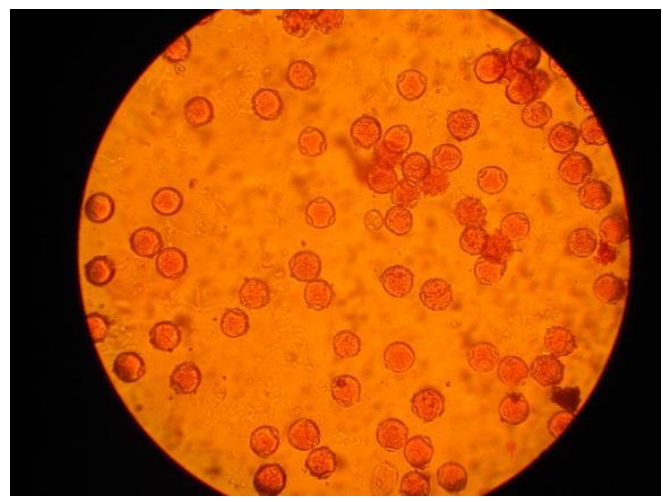

Fig. 7 H. caucasicus-fertile pollen grain. 


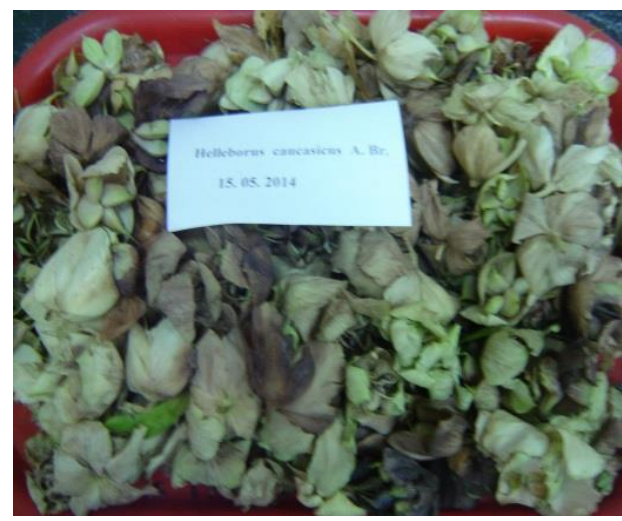

Fig. 8 Fruits and seeds of $H$. caucasicus.

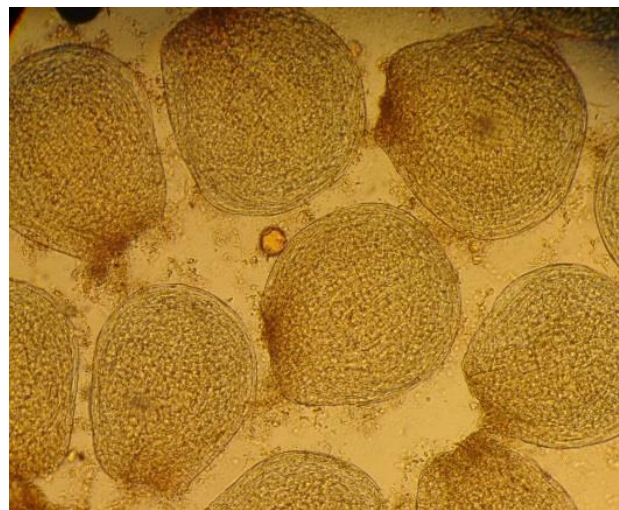

Fig. 9 Fertile ovaries of $H$. caucasicus.

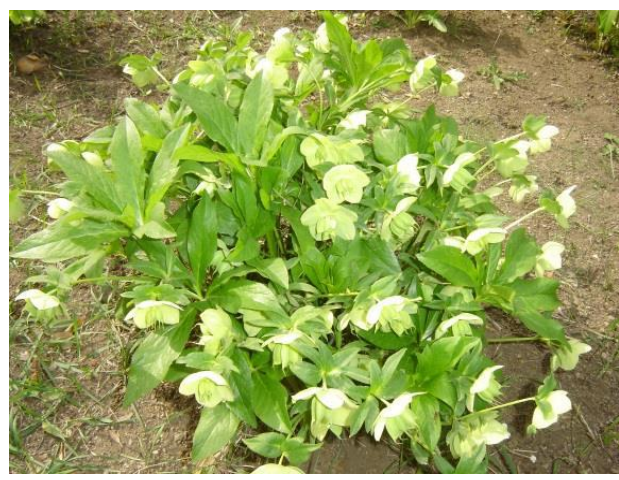

Fig. 10 H. caucasicus -in collection.

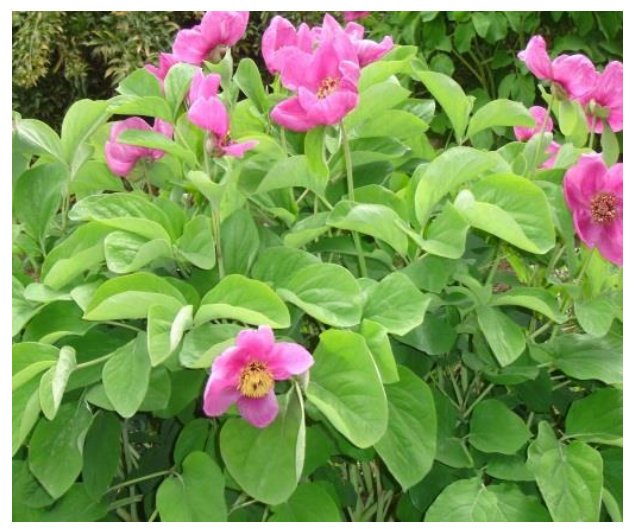

Fig. 11 P. caucasica in collection.

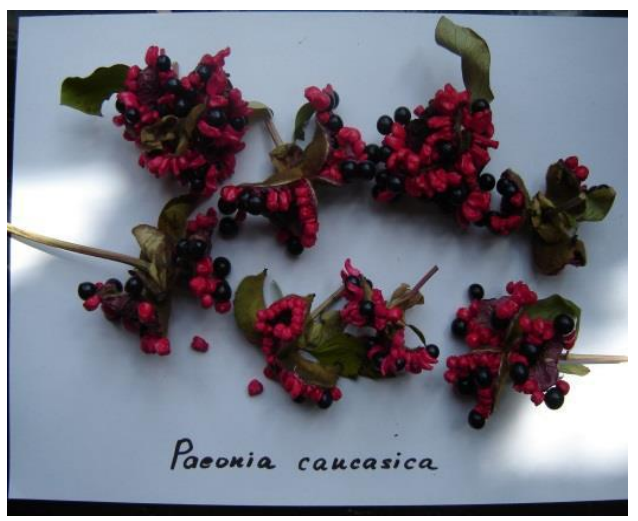

Fig. 12 Seeds of $P$. caucasica.

ovules number is $60-80$. Fertile seeds are a bit [12]. On the picture we see red and black seeds. The red color of the seeds (Embryo sac is no germ developed, the species is characterized by degeneration of endosperm). The species embryo is small in size, non-differentiated, of coenocyte type. Differentiation of the germ is very slow, so it takes a long of time to germinate seeds. In laboratory on the Petri are germination after 12th month. The seeds are in the ground and the plant rises 18 months after 20 months. Seeds fail to germinate on Petri dishes under laboratory conditions [6]. Percent of sprouting in pots is not low $-70-72 \%$. Seeds remain viable for a long time. Sprouts grown from seeds develop very slowly. Plant developed from seed starts flowering on the $6^{\text {th }}$ year.

\section{Conservation Works}

It is of urgent necessity to take conservation measures for these species through both ex-situ and in-situ protection methods. For this purpose it is of critical importance to collect data on the distribution of the above species and vitality and fertility of their populations

Ex-situ conservation activities have been undertaken: ex-situ collections of seedlings of target species are established on the experimental plot of the Department of Plant Conservation of the National Botanical Garden of Georgia and seed bank created Seeds are deposited at the National Seed Bank and the duplicates and herbarium vouchers sent to the Millennium Seed Bank of the Royal Botanic Gardens, Kew (Fig. 13). 


\section{Seed Bank and Living Collections}

Seeds of target species are to be necessarily collected in the wild. For each species a special data sheet is filled in, which along with geographic and botanical data contains comprehensive information about the sample, its habitat and the process of collecting. After the primary processing all these data are transferred into the electronic data base BRAHMS (Botanical Research and Herbarium Management System) and is electronically exchanged with the MSB and MSB DW (data warehouse).

The 500 seeds of target species are dumped in the National seed Bank and of the seed in the same quantity sent in the Millennium seed bank. In a live collection there are more than 1000 plants -each target species $[1,2,10,11]$

In addition, the National Seed Bank has a "Reserve" seeds (Fig. 7) and in living collection are seedlings which is provided free of charge to the interested organizations and persons. They are also supplied with information method about their propagation by seeds and vegetative.

\section{Conclusions}

Processes of seed production and seed multiplication have been studied of target species. The ex-situ base of the seed and live collection bank was created. The work is done in Great Britain within the framework of the "Millennium" Seed Bank Partnership of Kew Botanical Garden. The seeds are placed in the National Seed Bank, duplicates together with Herbarium sample are sent in the millennium seed bank. The live collection obtained from seeds is placed on the collection plot of Plant Conservation Department of the National Botanical Garden of Georgia.

Our research has been revealed. Our target, ornamental and medicinal species (tuber root-contains sapon in cyclamen in and glycosides, poisonous when fresh, but harmless after drying and is used in folk medicine) have strong anthropogenic stress.
Uncontrolled collection from wild populations reduces chances for self-regeneration of populations in the wild, especially Cyclamen vernum populations which naturally propagates only by seeds. We think it is necessary carry out its conservation work.

Future research-Cooperation between Georgian scientists and MSB-2 is currently on-going under the project "Saving the Flora of the Caucasus". Georgian botanists are keen to gather information on 700 medicinal species occurring in Georgia, collect the seeds and deposit them both to the NSB and MSB. All three target species are planned evaluation of populations with IUCN category parameters

\section{Referenses}

[1] Gagnidze, R. 2000. "Diversity of Georgia s Flora." In Biological and Landscape Diversity of Georgia. Tbilisi: WWF, pp. 21-32.

[2] Gagnidze, R. 2005. "Vascular Plants of Georgia." $A$ Nomenclatural Checklist.

[3] Grossheim, A. A. 1943. Medicinal Plants of Caucasus. Baku: Academy of Sciences. (Russian)

[4] Nakhutsrishvili, G., Gagnidze, R., Shetekauri, S., Manvelidze, Z., Memiadze, N., Kharazishvili, D., and Batsatsashvili, K. 2013. Red List of the Endemic Plants of the Caucasus: Armenia, Azerbaijan, Georgia, Iran Russia, and Turkey. Edited by Schatz, G., Shulkina, T., and Solomon, J. St. Louis US: Missouri Botanical Garden Press, pp. 362, 365, 369.

[5] Pobedimova, E. G. 1948. "Systematic Research of the Crimean and Caucasian cyclamen genus." Bot. J. V33. N2, pp. 220-228.

[6] Fanaskerteli-Tsitsishvili, Z. 1937. Medical Book. Metsniereba, Tbilisi (Georgian).

[7] Fanaskerteli-Tsitsishvili, Z. 1988. Medical Book Karabadini. Vol. 2. Tbilisi: Metsniereba, p. 1006. (Georgian)

[8] Kananeli. 1938. Medical Book. Tbilisi (Georgia).

[9] Herr, J. M. 1971. "A New Clearing-Squash Technique for the Study of Ovule Development in Angiosperms". Amer. J. Bot. 58 (8): 785-90.

[10] Rabotnov, T. A. 1960. "Methods of Investigation of Seed Propagation of Herbaceous Plants in Associations." In: Field Geobotanics. Vol.2. "Nauka": Moscow-Leningrad.

[11] Baskin, C. C. and Baskin, J. M. 2002. Seeds. Academic Press, San Diego.CA.

[12] Bowers, B. G. 1998. A Colour Atlas of Plant Propagation and Conservation. Manson Publishing, London. 
[13] Smith, R. D., Dickie, J. B., Linington, S. H., Pritchard, H. W., Probert, R. J. 2003. Seed Conservation. Turning Science into Practice. The Royal Botanic Gardens, Kew.

[14] Mikatadze-Pantsulaia, Ts. Gamtsemlidze, Z., Khutsishvili
M. 2006. "Reproduction Biology and ex-situ Conservation of Cyclamen vernum Sweet." Bulletin of the Georgian National Academy of Sciences 173 (2): 329-326.
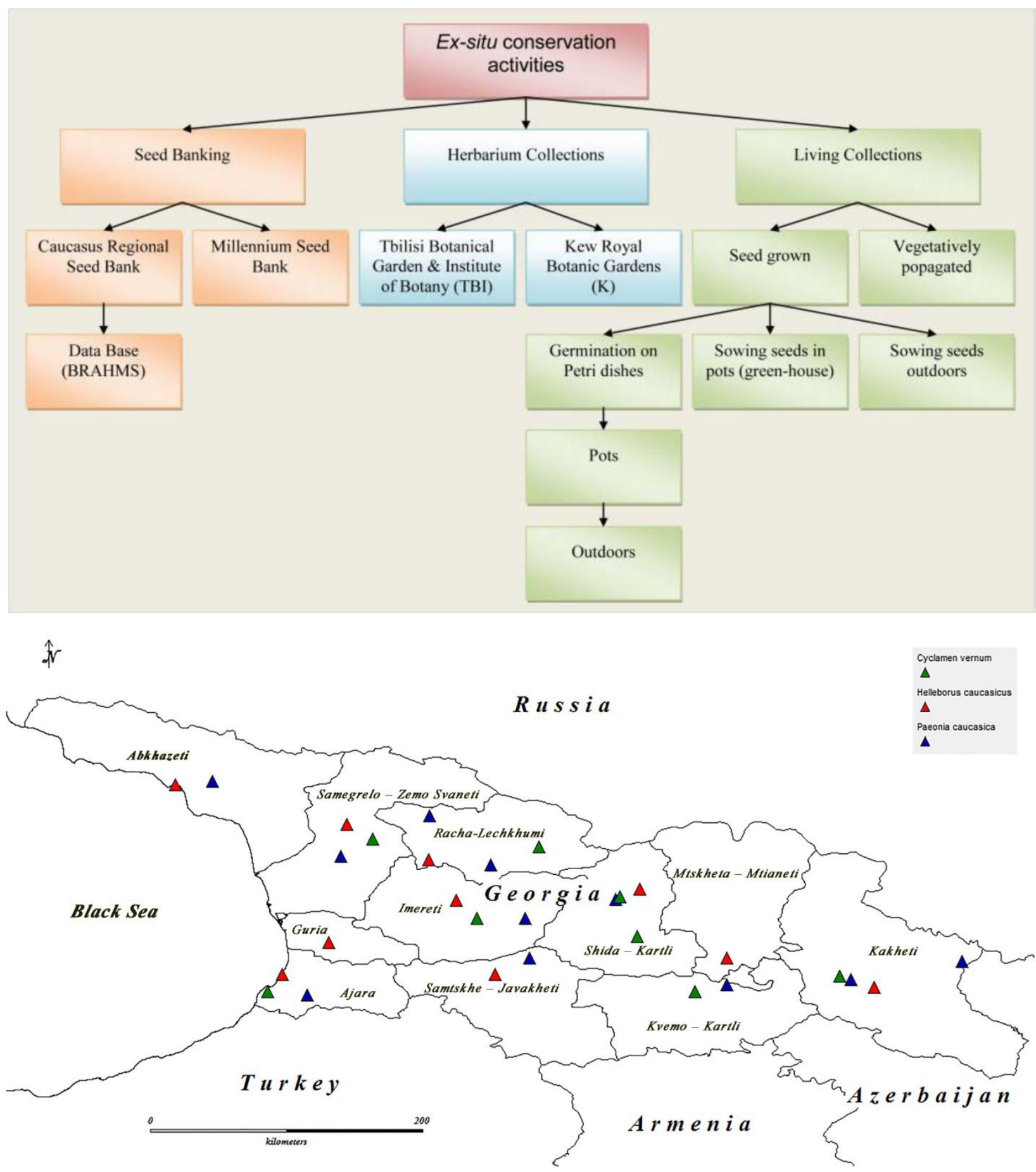